\title{
Skill, work and gendered identity in contemporary India: The business of delivering home- cooked food for domestic consumption
}

Nandini Gooptu and Rangan Chakravarty

[Accepted for publication on 21 August 2018 by Journal of South Asian Development. Publication expected in December 2018]

\begin{abstract}
This paper analyzes the meaning and significance of skills from the perspective of those who acquire and use them, going beyond dominant approaches to skill development as a strategy to enhance employability, productivity and economic benefit. With a study of home-based women entrepreneurs, who prepare food for delivery to customers' homes, the paper examines how entrepreneurial skills relate to gendered identity. While men operate with a market-savvy, commercial logic, women are animated by an ethic of personalized care and a family ethos of involvement in their customers' everyday domestic life. They cast themselves as expert practitioners of an inherited culinary tradition as well as being skilled in exercising a superior and inherent gendered capacity to forge emotional, nurturing, fictive kinship bonds with customers. Although this reproduces gender distinctions and may constrain the growth of women's business, they nevertheless cultivate these skills as a powerful mode of self-realization and developing a sense of self-worth. Bearing in mind the conception of human development as advancement of human flourishing, the paper concludes that, in approaching skill development, it is critical to consider the identity and perception of those who use skills, and the subjective, affective meanings attached to skills in a given social context.
\end{abstract}

\section{Keywords:}

Skill development, Skills, Work, Enterprise, Gender, Women entrepreneurs, Self-esteem, Selfmaking

\section{Introduction}

In recent decades, women in urban India have embarked on new forms of economic activity. They have capitalized on changes brought about by an increasingly liberalized and globalized economy, and by the rising demand for consumer goods and services from India's ascendant middle-classes, with their changing life styles and new consumption habits. One such activity is the preparation of cooked food and meals for delivery to middle-class homes for domestic consumption. The distinctive characteristic of 'home delivery' business, as it is called, is that food is cooked in the home of women responsible for preparing and delivering it to the home of customers. This home- 
cooked fare is distinguished from the commercially produced output of catering businesses, restaurants and takeaways. A recent Bengali-language feature film, Swade Alhade ('In Delicious Delight': Dir. Arindam Sil, 2015), depicts home delivery as a vehicle for a woman to empower herself, renegotiate gendered power relations and challenge oppressive patriarchy, by expressing herself creatively through the art of regional cuisine that she had learned from her mother. In the fictional narrative of the film, the culinary skills associated with home delivery business are represented as being deeply entangled with women's gendered identity, their autonomous agency and inter-generational inheritance of traditional knowledge through female lineage. Given the overwhelming importance of cinema in India's public culture, arguably this filmic rendition points to an important dimension to the social construction, cultural understanding and individual experience of gendered skills.

In light of this cinematic depiction, this paper probes skills through the experience of women home delivery entrepreneurs and asks what constitutes skill, and what is its purpose and meaning, for those who develop and cultivate skills of various kind. These questions arise from the recognition that skill is a contested and socially constructed concept with multiple interpretations from different vantage points (Lloyd and Payne, 2016). It is particularly pertinent to raise these questions at the present juncture in India when powerful new public policy initiatives are increasingly configuring dominant conceptions of skill. For over a decade now, the Government of India has been pursuing a much vaunted programme of skill development, in partnership with the private sector, resulting in an extensive proliferation of formal, institutionalized processes of training and certification in various kinds of skill. Such skills are believed to tackle unemployment among a growing youth population and also meet the demand for suitable workers in the country's modernizing, high-growth economy. The Mission Statement of the National Skill Development Mission proclaims the aim to implement a set of policies which 'aligns demands of the employers for a well-trained skilled workforce with aspirations of Indian citizens for sustainable livelihoods.' (Government of India, n.d.). In this resolutely utilitarian and instrumental approach, skills are understood as freely deployable assets, acquired through new forms of organized training, leading to enhanced employability and economic mobility, unencumbered by social and cultural influences. Not only does this view have a narrowly economistic and 'productivist' orientation (McGrath, 2012), it overlooks and undervalues preexisting or traditional skills and artisanal forms of apprenticeship. It also loses sight of the socially embedded and culturally defined nature of skills. Carswell and de Neve (2018) have aptly emphasized the analytical importance of attending to the 'social life of skills' and the 'socially mediated nature of skills acquisition processes' to understand how social institutions, such as gender, caste or age, enable or constrain the process of skill development, and influence subsequent employment outcomes. Recent research has further revealed that the acquisition of skills and their effective utilization for better economic opportunities and upward mobility are conditioned by social and power relations as well as the political economy of employment practices, such as flexible labour use (see articles by Ruthven and Sundar in this Special Issue). 
This apposite corrective to the instrumental official approach to skill development, however, sees the process of learning and using skills for work primarily through the lens of objective social and political economy determinants. It overlooks or underplays subjective and affective dimensions of skills, the importance of which is suggested by the filmic representation of home delivery business. It is also, of course, well-known that the experience and meaning of work, and related skills, are integrally related to one's sense of self and to both collective and individual identity (Joyce, 1987; Bauman, 1998; Heelas, 2002; Kocka, 2010). In other words, skills do not relate only to the technical ability to enhance productivity or earn a livelihood, but also, at the same time, involve subjective experience and emotional investment. This is recognized, in some ways, in current skill development initiatives, both globally and in India, with an emphasis on 'soft' skills. Indeed, the centrality of attitudinal change, emotional intelligence and selffashioning in new cultures of work is now a truism in management theory and practice. The critical role of affect and emotions in the economy has been sociologically theorized, for instance, through the concepts of 'soft capitalism' (Thrift, 1997) and 'emotional capitalism' (Illouz, 2008). As Illouz (ibid) argues, the modern corporate economy now relies less on the calculative rationality of the homo economicus and more on the emotional competence of the homo communicans. Illouz identifies the 'communicative ethic' to be 'at the heart of the corporation' in 'emotional capitalism', in which economic and emotional relationships are intertwined and mutually constituted. Emotions are, thus, analyzed as being critical to contemporary corporate capitalism, and the manipulation of affect and subjectivity in the labour process is understood as a form of corporate managerial control of workers (Hochschild, 1983; Macdonald and Sirianni, 1996). For skills training, in particular, Urciuoli (2008, p. 211) has analyzed how various 'aspects of personhood and modes of sociality', such as communication skills, teamwork and leadership, are engineered, commodified and aligned with corporate values and the demands of the workplace. Indeed, the transformation of subjectivity in this way is at the heart of contemporary forms of skill training across many sectors of the economy. However, as Urciuoli points out, these subjective qualities are 'divorced from their users' everyday social context' and decontextualized from individual life course (Urciuoli, 2008, p. 224). With this kind of instrumental orientation, formally acquired soft skills are pegged only to productivity, economic efficacy and the ability to work, and not concerned with the flourishing and constitution of individual lives. In contrast, this paper focuses attention on self-image, selfconception and self-making through skill as a part of individual biography. The aim is to enrich and extend the understanding of skill by analyzing the meaning and relevance of skills from the perspective of those who acquire and use skills.

With this in mind, in analyzing skills, this paper takes on board individual agency, subjectivity and affect, while also recognizing their interplay with social processes. It is acknowledged that individual subjectivity and exercise of agency are shaped by social, community or family relations, as well as social and cultural norms, ideas and expectations. For instance, social conceptions about the status or the value of particular kinds of work, or the role an individual is 
expected to play within the family, shapes one's self-understanding and sense of social worth. These, in turn, influence the ways in which individuals exercise their agency to make choices about work and skills. In recognition of this, in the literature on work and learning, Billett emphasizes the 'relational interdependence between social and individual agency' (Billet, 2006, p. 53). In this analytical spirit, this paper is concerned with the intersection and interface of social and personal factors. It explores how individuals exercise their agency to react and adapt to their specific contextual social position, and how they develop new forms of skill or advance their learning through the process of working, and in this way, also transform their selfconception, develop a sense of self-worth and recast their identity.

For the empirical enquiry of subjectivity, identity and skills, this study steps beyond the domain of formal skill training, where trainees or workers have already been socialized through organized training to instrumentalize skills with a 'productivist' orientation. Instead, attention is shifted to self-employment as a critical terrain of cultivation of skills and learning, from which important conclusions can be drawn about the nature and meaning of skills. The self-employed, notably women engaged in home-based enterprise, learn and cultivate a range of skills through work. The barriers faced by women in education and training are widely known, as are women's uneven access to the labour market and discrepancy in pay and working conditions between men and women (ILO, 2014). In public policy, the promotion of formal and institutionalized mechanisms of skill development are seen as powerful tools to level these inequalities and, in particular, to overturn entrenched labour hierarchies and overcome traditional occupational divisions based on gender (ibid). Paradoxically, in such policy interventions, women's skill, work and enterprise are often undervalued. For instance, dominant conceptions of enterprise are largely male gendered notions that purport to be universal and gender-neutral (Ahl and Marlow 2012; Bruni et al, 2004). The quintessentially Schumpeterian entrepreneur-innovator is a heroic male figure, operating with an economic rationality linked with the drive for profit and competitiveness - the desire to gain and win. This idea of the entrepreneur is associated with daring, risk-taking, decisive leadership, new knowledge, a break with the past and tradition, and a creative destruction of the old. From this perspective, women's enterprise and skills are often seen as lacking in ambition and in willingness to break new ground or to grow their business performance beyond subsistence ( ibid). Development interventions to promote entrepreneurial skills and stimulate innovation are frequently designed to rectify these supposed gendered deficiencies. Similarly, the significance of traditional or inter-generationally transmitted knowledge of women, as opposed to new innovation, and their psycho-social competence, as opposed to technical expertise, are seen as naturally occurring qualities or character traits of women and hence not considered valuable. Thus, women's skill and work that require high levels of emotional intelligence, such as in the interactive service sector, are accorded low status due to the limited use of technical or formally acquired skills. Countering these tendencies, it has been argued that the emotional work of women should be treated as highly skilled, for it 
demands autonomy and discretion at work, instead of the simply routinized use of technical or mechanical ability (Bolton, 2004; Gaskell, 1987).

Drawing upon these analytical perspectives, this paper delves into women's understanding of skills in entrepreneurial activity in order to reveal gender-differentiated values associated with skills as well as the specific motivations and strategies that drive skill development and use by women. Following feminist interpretations of the reproduction of gender relations and norms in terms of 'doing' or 'performing' gender, and not simply in terms of social structures (Butler, 1988, 1990), this paper explores how so-called traditional skills and gendered roles are embodied and practised by women in response to changes in the economy and the emergence of new market demands. The paper seeks to illustrate how gendered performance and identity can both liberate and limit opportunities and possibilities for women. At the same time, the paper examines how the deployment of gendered skills is inextricably interlinked with women's selffashioning and self-image.

This research was conducted in Kolkata, in the regional state of West Bengal, where home delivery businesses are now thriving in a number of localities and have emerged as an important source of livelihood for women. Lengthy, open-ended, in-depth, qualitative interviews were conducted with women entrepreneurs, allowing them to recount their motivation, experience and approach to home delivery and to describe the development of their business and relationship with their clients. Although it is unusual for men to undertake home delivery business, interviews were conducted with some of them who engage in this as an ancillary occupation, as well as those who had started home delivery in support of female relatives and then diversified or scaled up to commercial catering operations. Since very few men undertake home delivery and such men are difficult to find, one of them was interviewed in the nearby small town of Bolpur, where he runs his business. These interviews with men offer useful points of comparison between the perspectives and experiences of men and women and bring out the gendered dimension of skills. The full range of interviews covered home delivery businesses of varying sizes and scales, ranging from fairly small operations with a limited clientele of around a dozen to larger enterprises with a customer base of around a couple of hundred. There is also a class difference in the clientele served by these various enterprises. One business, that mainly serves migrant students, offers a fish meal for INR 45, while a business in an affluent area, serving professional and retired families, charges INR 120 for fish and more for chicken and meat dishes. Pseudonyms have been used for individuals and businesses mentioned in this paper.

\section{Women entrepreneurs in home delivery business}

Three typical, but contrasting, cases of home delivery entrepreneurs are presented in this section to illustrate the nature of women's entry and work in home delivery business, in terms of their life course and self-perception. 
Bishur Didi (Bishu's elder sister), as she is known to all, migrated to Kolkata with her children and mother-in-law from neighbouring Bangladesh in the 1980s, when many Hindus left the country due to political problems. She was not accompanied by her husband, the reasons for which she did not explain. It appears that her husband worked on land in Bangladesh, but the income was not sufficient to remit any money to Kolkata to support the family. Bishur Didi had to raise a son and a daughter on her own. Her two younger brothers, one of whom is Bishu, were already in Kolkata, which had prompted her to seek refuge in the city with them. This had earned her the local identity of being 'Bishu's elder sister'. The brothers were of very modest means and owned a small shop. To help her support herself and her children, the brothers encouraged her to produce ready-made snacks on a small scale, to be packaged and sold at their shop. She took this on, for she felt confident that she could use what she saw as her strength, namely, her cooking skills. She explained: 'My brother has a shop. He said, "Snacks like nimkis (munchies made from flour dough) sell well at my shop. If you make those things, you could do well". Now I was quite used to [making them] as I had learnt from my mother. As a young girl, I would watch my mother and learn to make them...'

In this way, armed with 'inherited' learning and traditional skills as valuable resources, Bishur Didi launched into her nascent business. This snack initiative proved to be a success and gradually, she shifted to home delivery, relying on her existing cooking skills and responding to an emerging demand for home delivery in the vicinity of her neighbourhood, particularly in an adjacent large housing complex of well-off professionals and retired elderly people. Her brothers and son helped with delivering food and accounting, for she felt unqualified to take these on. She described it as back-breaking work to scale up her cooking, but she persevered and built up a stable client base: 'I cannot tell you how much hard labour I have put in in my life in this work'. As her business thrived and she began to earn a steady income, she was able to secure a loan, with the help of her brothers, to buy a small two-bedroomed flat for herself and the children. In subsequent years, she gradually paid back the loan. Her children grew up. Her daughter is now married. Her son, who still helps her, is a graduate and works in a cinema hall as an accountant. Her maternal responsibility of child rearing fulfilled, and with some savings and a secure roof over the family's head, she has now contracted the size of her business, retaining only around 20 regular customers and catering for special family occasions on request. Reflecting on her life, she commented:

When I started the home delivery business, I used to live in a rented house. Our economic condition was very bad. ... I am blessed with my children. My husband did not do much. I had to run the family. My brothers ... managed to arrange a loan of 2,50,000 Rupees; I bought the flat. I paid back the loan through my home delivery and reached the position I enjoy today. Now my son has got a good job, so I have brought down the size of the business.

Family responsibility, rather than profitability or business expansion, is clearly the overwhelming motivation and incentive in her home delivery venture, coupled with the role of kin and family - her 
brothers - as an enabling factor. The hard work she had had to undertake, as the female breadwinner for the family, brought rich dividends from her point of view, not in financial returns or business success, but in terms of her self-identity of being self-reliant and successful in bringing up her children well and securing a family home, by dint of her own struggle and skills. Explicitly or implicitly, she mentioned this, with a tone of pride and sense of achievement in her voice, many times during our conversations. For instance, referring to her past hard-work and determination, she said:

In those days I knew that I had to do it - 'Kortei habe' [I must do it; I have no option]. There have been days... like one day ... I had to supply 200 food packets - four puris [fried bread], potato curry and sweets. Now, it is not easy to make so many puris. I made them through the night.

Asha is a poor housewife, who lives with her husband and daughter and runs a home delivery business. Although very shy, unassuming and far less expansive than Bishur Didi in describing her hard work for the benefit of her family, Asha clearly takes pride in her business for the contribution she makes to the family. As she explained, her husband is a small-time building contractor, with variable, seasonal work. With irregular and low family income, Asha sought to use the only useful skill she thought she possessed - that of cooking - to augment and supplement the family's income. The customers of her home delivery business, now running for over a decade, are mostly students from distant places who have temporarily migrated to Kolkata and who live in rented accommodation in Asha's locality. These students have no kitchen facilities and cannot afford restaurants. Her food is simple and inexpensive, as appropriate for her clients of limited means. Her husband helps her with shopping, delivery and accounts. Being reticent in managing affairs outside the home, Asha concentrates herself entirely on using her skills to prepare food. Her daughter, who goes to college, is interested in cooking new, creative recipes, which she watches on television. However, these are not used for business, since the demand is for inexpensive everyday, comfort food of the kind usually provided to young people by their mothers at home. There appears to be no ambition on Asha's part to scale up or diversify or target a wider clientele.

If these women started and sustained their home delivery business to maintain and support their families, Grandma's Kitchen was started for a very different reason, but still related to gender. The entrepreneur, Indira, who is of middle-class origin, was driven by a sense of gender solidarity with other women workers to help them cope with their domestic duties. She started her working life at an all-women's branch of a nationalized bank. Here she noticed how difficult it was for her colleagues to cook at home in the morning before work and then again in the evening after work. She then came up with the idea of home delivery of everyday food as a venture that would relieve working women of the daily task of cooking and help them to sustain their domestic and family life with her help. She launched a kitchen on the terrace of her own house to serve a small clientele of 
her colleagues. Her husband, a government employee, helped her in his spare time. Gradually, over a couple of decades, the business grew to a major enterprise, supplying home-food in a large catchment area around her house to affluent professional and retired families, including a substantial number of elderly individuals and couples who live on their own. Her client base has now reached nearly 200, a large subset of whom requires food on a given day, and the business employs more than 12 cooks and delivery staff. Her son has joined the family business, which he considers a viable and lucrative career opportunity, especially with the recent expansion of the business to cater for domestic celebrations and family feasts, such as weddings or child birth. While the main, large-scale wedding reception still remains the domain of commercial caterers, Grandma's Kitchen supplies food for traditional, family-oriented ritual occasions associated with wedding, birth, etc. Unlike Bishur Didi and Asha, the owner of Grandma's Kitchen emerged as an entrepreneur beyond the role of a supporting mother or wife. This expansion of her business was, no doubt, possible due to her middle-class social and spatial location, which enabled her to mobilize capital and resources, and to tap into an affluent clientele in her neighbourhood. Importantly, however, a gendered view unambiguously underpins her business, which she sees in terms of contributing to the family and domestic life of her clients. For her, like the others, the gendered idea of care is at the heart of her business and her self-image, as we shall further see below.

These cases show that women's home delivery businesses relate, to a large extent, to their gendered social location and their familial or parental roles. Usually husbands, brothers or sons manage marketing, finance and delivery, because women either face impediments in accessing the external world of money and markets without male support or they have a perceived sense of inability to handle the so-called 'business' part of home delivery, in contrast to the cooking and client-care part, in which they see themselves as proficient and possessing innate skills. Despite the differences in scale and success of their home delivery ventures, all these women rely on their knowledge of cookery, and also importantly on their skill in forging caring personal relationships with their clients. The following sections examine this point.

\section{Demand for home delivery}

Women's conception of the relevance and value of particular skills that they deploy in home delivery relates significantly to the specific nature of demand for home-cooked food from their customers. The owner of a home delivery business noted that a decade ago there were only one or two such enterprises in their own locality, but now over 30 units were vying for business. This observation is very much in tune with national findings about the growing demand for food and beverage services for either eating out or buying in to eat at home. A recent report notes that the Indian food retail industry is the sixth largest in the world. It has been increasing at a steady pace of around 15 per cent annually, while the combined food and beverages market currently enjoys a compound annual growth rate (CAGR) of 23-24 per cent. The report estimates that the restaurant industry is growing at such a fast pace that it is expected to contribute over 2 per cent to the total 
GDP of India by 2021 (KPMG, 2016). Such spectacularly rising demands are attributed to a rapidly growing young population, rising income levels, urbanization, health consciousness in food consumption, interest in new culinary experiences, busier lifestyles and preference for readily available and prepared products, and so on (ibid).

The growth of the home delivery business in Kolkata is, no doubt, a part of this wider, nationwide surge in the food industry, but women engaged in home delivery point out specific local factors, relating to changes in demography, migration pattern, family structure and gender relations. Home delivery entrepreneurs identify elderly people, living on their own, as one of the key groups needing daily food that is no longer provided by family members. The population of those aged over 60 is largest in Kolkata in comparison with other major cities in India (Sen, 2015). Due to the lack of economic opportunities in Kolkata for educated Bengali youth, many have migrated out of the city, leaving behind the previous generation. For this ageing population, an urban care industry has gradually emerged that includes the organized provision of home help for healthcare and everyday domestic service (Pal, 2016). The supply of cooked food by home delivery businesses is a part of this new care economy to compensate for the attenuation of extended families. Demographic forces are compelling aged families to eschew their cultural preference for food cooked in their own home and instead imbibe food cooked in the homes of external providers through home delivery. At the other end of the demographic spectrum from the aged, middle-class and poor youth have flocked to the city in search of education and training for employment. As temporary migrants without families and living in rented accommodation, they require regular supply of daily meals. Here, as in the case of the elderly, home delivery businesses act as surrogate families by providing everyday 'home' food. Thus, for instance, an obvious sense of responsibility, akin to feeding one's own family, pervades Bishur Didi's approach to her business: 'On some days, even if an order comes after I have closed [the kitchen] .... somehow, I would manage, some dal (lentil soup) in the pressure cooker [for swift cooking], make eggs [that are readily available] or something else. You have to feed them [the clients]. Otherwise they will go hungry.' Indeed, she and others see themselves as performing the vital function of caring for the elderly and the young, and helping to create a semblance of 'home', in the context of absent family members.

In addition to the above, one of the important causes of demand for home delivery is attributed by home delivery businesses to the changing role of women within the family. Home delivery vendors point out that housewives do not any longer have the time or inclination for arduous cooking or for the supervision and management of food preparation by hired cooks, even though these have been essential gendered features of the role of housewives (Donner, 2011). Women's increasing employment, especially in the upper segments of the urban, educated, professional middle-class, may partly be contributing to this change. However, women's full-time employment or professional career still remains limited across the middle-classes. Nevertheless, there is a growing acceptance and normalization of women's education, their pursuit of careers 
and paid employment as well as their outward facing activities and public roles. As GangulyScrase argues in her study of lower middle-class Bengalis: 'One of the crucial markers of emerging class identity among this fraction of the middle-class is the desire for the public visibility of women and their relative freedom to pursue careers' (Ganguly-Scrase, 2003, p. 554). Moreover, quite apart from women's work outside the home, it is now widely acknowledged that their role within the household is significantly altered and much expanded, with epithets such as 'domestic goddesses' (Donner, 2008), 'Chief Executives of the household' (Bijapurkar, 2008, pp. 171-5) and 'enterprising housewives' (Gooptu and Chakravarty, 2013) being applied to them in the analytical literature. As Donner shows in her studies of middle-class Bengali families in Kolkata, the post-economic liberalization period in India since the 1990s has seen an extension of women's domestic functions and, in particular, a significant enhancement of their maternal responsibility to mould properly educated and healthy children, suited to today's competitive world. Women now also play an important, and unprecedented, role in the maintenance and improvement of the family's status and class position in a new consumerist milieu (Donner, 2006, 2008, 2011). In this context, there is now greater importance attached to women's public presence and presentation in augmenting a family's social standing. For instance, one home delivery vendor observed that, among the newly rich clientele, husbands do not like the grooming and appearance of their wives to be compromised by the heat, oil and grime of everyday cooking, affecting their skin, hair, hands and nails. This resonates with the eagerness with which women of middle-class families now seek to participate extensively in reality TV shows, with the approval of their families, as a form of accumulation of public recognition (Gooptu and Chakravarty, 2013). In a different, but related, vein, some of our informants claim that watching serial dramas and reality shows on TV is a major distraction that keeps women away from their kitchens and the daily grind of food preparation. Whether or not this is an extensive phenomenon, it does points to the importance of the growing availability of various leisure and entertainment options, inside and outside the home, in altering the priorities of women with regard to their domestic duties, including food preparation.

According to many of our informants, the key factor in the demand for home delivery is the changing relationship between housewives and household help. Most housewives rely wholly or partly on domestic help for the preparation of food, rather than doing it themselves (Donner, 2011). However, this arrangement is under considerable strain in Bengal, with significant recent change in the terms of employing domestic servants (Ray and Qayum, 2009). The cost of hiring domestic help has been escalating and availability is believed to be scarce. Domestic workers frequently charge separately for each chore, for example, doing the dishes, cleaning floors, washing clothes, cooking, etc. Moreover, cooks are no longer willing to spend time on complicated cooking as most of them work part-time in several households. As a result, it is, often, far more economical to buy in cooked food than employing cooks at home. In many families, the otherwise busy housewife prepares the easy and basic staples of rice and lentils, while other items are ordered for home delivery. 
In addition to changes in gender dynamics and in the family economy of hiring servants affecting the preparation of food at home, Ashis Nandy notes, 'The older models of socialization are becoming recessive in urban, middle-class India and preparation of food is becoming less of a matter of apprenticeship at home for daughters, daughters-in-law, and younger women in the family...' (Nandy, 2004, p. 15). Housewives not only lack time, but also more importantly, no longer possess inherited knowledge and skills to prepare complicated items from Bengali and other cuisine. They are, thus, also unable to train domestic staff, even when they are available. Home delivery comes into its own when families wish to consume traditional Bengali dishes, either regularly or on special occasions. Restaurant takeaways or commercial caterers are expensive. For instance, a takeaway meal for two from a restaurant would cost between INR 350 and INR 700, compared to INR 200-300 for home delivery food. More importantly, restaurant food is considered too rich and spicy for domestic consumption. Besides, restaurants do not supply regular meals nor cater to personalized dietary needs and preferences. Middle-class housewives, thus, supplement or replace their own food with apparently home-produced fare, in order to enhance their efficiency and standing in the home, fulfil the demands of their everextending duties, and compensate for their own lack of skill or time.

\section{Gendered identity and subjective skills}

With urban Bengali middle-class families undergoing major changes relating to gender roles and family structures, the demand for home delivery is growing steadily. What families consume from home delivery units is not just 'home-cooked' food, but they also seek to 'buy' the possibility of producing new forms of affect, relationship and identity within the domestic milieu. The culture of preparing and consuming food at home is deeply entrenched in Bengali middle-class domestic practice (Donner, 2011). However, by accessing home delivery, families are shifting towards a new formulation of the very idea of the home as a specific kind of sociality defined only through the consumption of food, separate from the act of preparation and production within the home. Srivastava has argued that the home and the family are now at the heart of middle-class consumption, and the key site of articulation of national identity, as aptly captured in his coinage of the appellation 'national domestic' (Srivastava, 2012, p. 75). Middleclasses express their social and class status and accumulate cultural capital by securing goods, services and expertise from the market to enhance all areas of family and domestic life. An important facet of the construction of this 'national domestic' identity is the imbibing of food within the home from a much enriched and expanded menu, driven by the increasing commercial availability of myriad types of food in the wake of economic liberalization and globalization. However, to maintain the pretence and conceit of the home and the domestic milieu as an intimate domain, distinct from the outer, public world of the market, families rely on home delivery food when eating in, for it is construed to be produced in the 'home', even if that home is of the vendor not of the consumer. This reliance on home delivery can be interpreted as a form 
of what Arlie Hochschild (2012) has called the 'outsourced self', whereby services are purchased to fulfil tasks that are associated with intimate, private and domestic life and that were previously performed by family members.

Within this context of a specific kind of demand for, and relevance of, home delivery in middle class homes, the success of home delivery entrepreneurs rests, not only on their cooking expertise, but also, to a large extent, on their culturally-rooted, gendered subjective skill to understand the changing cultural meaning of food in the domestic milieu. Home delivery vendors have come to appreciate the needs and preferences of the customers, adapted their working practices accordingly and developed suitable skills. This process of cultivation of their skills reshapes their self-perception as experts not only in cooking, but also in caring, which is not merely a business strategy, but lies at the heart of their self-fashioning.

Home delivery entrepreneurs proudly proclaim their special skill and expertise in cooking food that is projected by them, and perceived by their clients, as culturally authentic and homely (gharoa), yet nutritious, healthy, delectable and hygienically prepared. By attending to both the well-being and the culinary satisfaction of all members of the family, home delivery businesses help to fortify the very idea of the home as an idealized safe and happy domain, and a protected, wholesome and nurturing space. In this, home delivery plays to the increasing preoccupation in middle-class families with health (Donner, 2011). One entrepreneur said: 'The restaurants think that you can make food tasty only by adding spices and oil. But I make food tasty without spices and that is what my clients appreciate. They tell me no one can make such tasty food. That is why I have clients who are with me for seven, eight years.' Some entrepreneurs claimed that cooking, which is essential for the family's health, should not be left to hired cooks from poor backgrounds with no conception of hygiene. Most home delivery vendors are, of course, not of middle-class origin and many come from similar social classes as hired cooks. To differentiate themselves unambiguously from hired cooks, they claim both superior cooking expertise and knowledge of hygiene and nutrition. Their food is thus billed as suitable for consumption by young and old alike day after day without upsetting stomachs: 'I have been doing this business for 10 or 11 years, but till date no customer has said, "I have been unwell after eating your food, or I do not like it"... no one says that.'

The distinctive value of home delivery food is associated with the inherited and inherent cooking skills of women that have stood the test of time. Still, such food needs to be augmented with touches of novelty from time to time. This is required to match the growing desire in middleclass families, especially among the young, for diversification of menus, arising from the globalization of their eating experiences and tastes (ibid). In response, some entrepreneurs have started supplying Mughlai (north Indian) or Chinese food, European style salads, etc., on special occasions. In expanding their menus in this way, home delivery vendors seek inspiration from cookery programmes on television to gain information and tips on international and regional 
cuisine from beyond Bengal. Equally importantly, to enhance the appeal of regular meals, they build on their existing knowledge to improvise complex, skillfully executed dishes and menus, by adding innovative embellishments to their traditional Bengali repertoire. Asha, for example, works hard to develop a weekly menu plan to ensure variety for her young student clients, without raising the price. She offers meat, chicken, fish or egg dishes on different days of the week. Saturdays are set aside for vegetarian meals in deference to the religious beliefs of her customers, many of whom do not eat non-vegetarian food on that day. Like Asha, Bishur Didi spoke with obvious passion about the complex ensemble of food she tries to purvey on a daily basis.

The menu is different every day. Like, today is Friday, so there will be fish. But someone would call up and say, please give us meat for three people. Then I shall do that. Generally we give meat only on Sundays. Today, I have made a mixed vegetable curry, a cabbage dish, a paneer (cottage cheese) preparation with soya beans, and fish and dal and some fried potatoes. The day I make potato fries, I do not give them [the customers] aubergine fries, then one day I fry papads (poppadum). Some days it is fried patal (pointed gourd). Because you do not want to eat the same thing every day.

Going further, Bishur Didi recounted her menu plan for the following day, with much relish and a chuckle of delight. She evidently delved deep into Bengali cooking culture for inspiration to assemble various usual and unusual ingredients to conjure up unique tastes and flavours: 'Tomorrow I am going to make chal kumdo-r tarkari (stir fry with ash gourd) and a kind of mixed vegetable curry with lau-er $\operatorname{dog} a$ (stalk of bottle gourd). Tomorrow is Saturday, vegetarian day, so I will make something like dhonkar dalna (lentil cake curry) with daler bada (lentil cakes), fried aubergine, fried karala (bitter gourd) and chholar dal (soup with split Bengal gram).

In using her skill and creativity, in this way, Bishur Didi seeks to elevate the quality of seemingly mundane, quotidian fare to almost an art form. Inherited or socially transmitted knowledge is not simply reproduced but subjected to creative reinterpretation to develop new levels of mastery. The driving force here is not so much the development of new recipes to gain recognition, better customer rating or market leverage, as a commercial chef might do, but to ensure the clients' continued enjoyment of home delivery food without monotony. In this endeavour, Bishur Didi seems to visualize an individual client who will enjoy eating her food and with whom she has an emotional connection, rather than imagining an anonymous customer as a generic entity who just buys her product. She appears to be animated by a desire to treat customers as she would regale her own family members with her food. This spirit extends to bespoke catering to meet special needs and diets. There are often requests, such as: 'It is raining today, so please send me khichuri (kedgeree) and fried aubergines.' Or 'I have come down with a fever, so can you give me a light fish stew today, please?' Home delivery entrepreneurs express 
their particular satisfaction in possessing the skill to respond to such special needs and requests made within the framework of highly individualized and personalized relationships between vendors and clients. Janeja describes a strong preference in Bengali families for particular palates of taste and culinary repertoires that they see as 'normal' and that they associate with their own brand of Bengaliness in food culture, originating from either western or eastern Bengal. This is reflected in their expectation from hired cooks, who are tasked to produce 'food like ours' and become attuned to the families' preferred tastes, recipes and modes of cooking by relinquishing any trace of their own cooking habits (Janeja, 2010, p. 50). Home delivery businesses may or may not be able to replicate the exact tastes desired by each of their customers, but their overt and stated willingness to cleave to the demands of their customers and to offer bespoke food seem to render their food 'normal' and 'like ours', to use Janeja's term. This contributes to both cultural affinity and personal bonding between the vendors and their clients.

From the perspective of home delivery vendors, their food is, above all, associated with trustworthiness, reliability and honesty for providing superior quality ingredients and products as well as ample quantity at a fair price, unlike restaurants and caterers with commercial motives. Indira of Grandma's Kitchen is unequivocal on this subject:

I think two things are important. One is honesty and the other is to think what would I like to eat when I am hungry. You have to think of the person who is paying you to eat, so that their money is not wasted. You have to ensure these things. ... I supply mochar tarkari (stir fry with plantain flowers) for six Rupees, which three people can share. A restaurant will add some decorative flowers to it [for better presentation] and sell it for double the price.

The entrepreneurs claim that they never compromise quantity or quality for profit, since health and adequate nutrition are paramount, along with taste. Trust, as the pivot of the relationship between vendors and clients, is cemented with a loyal personal relationship, as described by one vendor: 'If I take a day off, they [the clients] get upset. For the days when I am not open [i.e., the business is closed], they would order in a few days' food in advance and keep it in the fridge, but will not order food from elsewhere.' This enduring relationship relates, in large measures, to the personal investment and involvement of home delivery vendors with their clients' family and everyday life that encompass, for instance, health issues, requirements for family celebrations and ritual events, cover for the leave of domestic help, and so on. One home delivery vendor commented, 'My [clients] are mostly old people, so they like light preparations, cooked with green chilli [not red chilli powder], nothing too hot; some like their food a bit sweet, some do not.' Another vendor explained, 'During shaadh (ceremony to honour a woman before giving birth) for a daughter, there are requirements for shukto (appetizer stew), fried fish, fish head, rice pudding - ... these are customs - similarly for aiburo bhat (ceremony held before wedding) or annaprashan (a child's rice-eating ceremony)...' 'Then there are special requests like, "Today we need ten plates of meat and pulao". Then I supply that.' 'Then there are people whose maids 
have taken leave. [They call me and say,] "Didi, you have to give us food for 10 days because our maid is on leave". In all this, home delivery vendors, in effect, function not as mere caterers of food but as members of an extended network of family and kin who support their clients in their daily life and regular needs.

This family ethos of home delivery is reinforced by a spirit of caring with a personal touch and building an emotional link with the customer. This is not only a major component of their skill and but also critical for the self-construction and identity of the entrepreneurs. The owner of Grandma's Kitchen, who invokes a familial relationship in the very name of her business, said that she insists on putting the food into containers herself. Apparently, if this is done by some hired help instead of her, the regular customers discern the difference immediately and ring her up to complain: 'You did not serve the food today, did you? I could tell from the amount and the style of serving'. According to her, particular care is needed to serve rice in the right quantity and to fill dal in the container to the correct level so that it does not overflow as the lid is taken off. This example of personal care - of doing everything 'with one's own hand' (nijer hate kori) was echoed by Bishur Didi:

I do not allow anyone else to cook or even to serve the food in boxes [for delivery], because I know exactly how to serve the food. And if some day, I am not well and someone else has put the food in the box, customers would say, 'Didi, today you did not put the food in the box, did you? Are you getting things done by hired helps?' I say, 'No, I am not well, so I asked my daughter to put the food in. Maybe she has not been able to do it properly'. They [the clients] are good people. They would say, 'There is no problem, you will serve tomorrow yourself, no?' I say, 'Yes'.

Even when hired help is employed due to the rise in number of clients, as in the case of Grandma's Kitchen, the owner emphasizes that she trains her employees carefully and personally so that they work with the same ethic of personal care as she does, thus alluding to the importance of inter-generational and inter-personal transmission of gendered skills within the setting of women's enterprise.

If health, nutrition, creative cooking skills, personal care, homely authenticity and a putative family ethos are all important components of home delivery, another significant aspect is a strong nostalgia for, and an urge to cling to, what is seen as the rapidly disappearing art of traditional Bengali cuisine - Bangla ranna. The owner of Grandma's Kitchen consciously caters to this sentiment through the name of her enterprise that invokes a sense of wisdom, experience, tradition and history. As noted above, Bengali culinary tradition has been gradually eroding, partly due to changing gender and family relationships and partly under the influence of other genres of cooking. However, according to our home delivery informants, when eating in, there is a strong preference to savour traditional Bengali food. In the homes of the elderly, where the demand for home delivery is high, knowledge 
of Bengali cuisine may still exist, but cannot be put into practice due to the loss of capacity of aged women to cook or supervise cooking. Yet, it is in these families that supposedly quintessential Bangla ranna is much coveted, not only by the elderly who are habituated to this genre of cooking, but also by migrant members of the family when they return home to their elderly relatives. Among young migrant Bengalis and their families, there is a strong valorization of traditional Bengali food, with which the idea of the home and desh (homeland) is enduringly associated (Janeja, 2010). Faced with what is seen as the corrosive impact of migration and global food on regional cuisine, Bengali food has emerged as a marker of middle-class cultural pride, with which to reinvent their cultural identity and preserve their heritage as Bengalis.

Not surprisingly, women entrepreneurs often equate the demand they receive for 'home food' with a desire for traditional delicacies that are becoming scarce at home. Some items are part of daily fare, while others are sumptuous specialties, consumed once in a while, and are both time-consuming and labour-intensive to prepare. In this context, home delivery women are proud of possessing traditional culinary skills to produce Bangla ranna. Reference to demand for 'shukto' appeared in almost every interview we conducted. Shukto is a stew served as an appetizer, consisting of bitter gourd, papaya, sweet potatoes, plantain and other vegetables, sautéed with mixed spices and boiled in milk. It is a typical item from the traditional Bengali repertoire, requiring knowledge of special ingredients and techniques, and seldom now cooked at home. Other such dishes, mentioned by our informants, include: Paturi - fish grilled with mustard sauce and wrapped in banana leaves that requires accurate timing; Mochar Ghanta - a preparation consisting of plantain flowers that have to be skilfully and painstakingly chopped into very fine pieces; Enchod - cooked with unripe and sticky jackfruits, demanding specialist knowledge and experience to execute properly; Dhonkar dalna - a curry with lentil cakes that involves many complicated operations and stages of cooking. In additional to these delicacies, some entrepreneurs mentioned traditional ways of eating food that they help to sustain: 'One IIT engineer [mark of an established, educated Bengali professional] told me that for my son's wedding, I shall serve food on banana leaves spread on terracotta plates'. Home delivery entrepreneurs, thus, see themselves as playing a central role in ensuring the survival of both Bengali cuisine and traditional dining practices. Indeed, alongside helping to consolidate the idea of the home as a safe haven of nurture, they are contributing to the constitution of the home as the core of traditional Bengali identity, as defined through its culinary culture, a role previously performed by housewives (Donner, 2011). Scholars have emphasized the nationalist construction of the home in colonial Bengal as the pristine core of tradition and spirituality, with women at its heart, and untouched by colonial modernity (Chatterjee, 1994; Sarkar, 2001). The imagination of the 'home' as the preserve of tradition in home delivery business resonates with this historical understanding and helps to reproduce it in a contemporary context of globalization and marketization, with a specific orientation around food.

It is evident from the above account that home delivery women highlight their technical culinary expertise as well as their affective, subjective skills, both of which are closely aligned with their own 
gendered identity and role, and are central to the construction of their self-image and self-esteem through their work. They point with pride to their specialist cooking skills to produce healthy, authentic, traditional food, on the one hand, and on the other, express great pleasure at their skill in being able to generate personalized caring, nurturing relationships with their clients, thus upholding the core values of the family and the home.

\section{Personalized caring versus professional catering}

Women home delivery entrepreneurs, clearly, capitalize on what they see as feminine virtues and strengths, including traditional knowledge, and the essential caring attributes of their gender. This feature becomes even more obvious from the significant gendered differences in orientation to home delivery business between men and women. Men, in contrast to women, have an altogether different approach that sheds light on the gendered dimension of skills deployed in home delivery. As seen above, in most cases, women launch their home delivery business in support of the family, where their putative natural skills in the domestic work of cooking and caring are extended to start a smallscale business in order to tackle financial needs. Once men step in, they seldom, if ever, cook or claim to have any knowledge of cooking, and usually the business grows in a more impersonal direction and into the traditionally male domains of public catering or the hospitality industry, where customer service, rather than personal care in a familial mode, is the watchword.

Keshab Babu is a successful businessman, with several enterprises, including corporate catering and dealership of a major milk supply chain in the eastern region of India. He does home delivery during festive seasons only, such as the annual Durga Puja festival, when it is most profitable. At this time, customers order special food and delicacies for celebratory family meals at home, for which they are willing to pay a high price, instead of eating out. During the Puja, Keshab Babu targets customers in his catchment area by dropping leaflets in their post boxes. He clearly aims at specialist, high value segments of the market for home delivery and develops his business in directions other than that of everyday 'homely' food.

Gourmet Food is a business in Bolpur near Kolkata. Their home delivery customers are affluent Bengalis as well as upmarket tourists, since the town enjoys a regular tourist traffic as the location of the home and university of the Nobel Laureate poet Rabindranath Tagore. Their food is expensive and projected as an exclusive product, access to which is a status symbol. The owner relies on professional image management of the company and on branding the enterprise as being run on scientific management principles, with modernized equipment and kitchen facilities, which customers are invited to visit, and the use of computers for managing orders, inventory control and day to day accounts. The emphasis here is on modernity, technical advancement and a professional approach to service and business innovation, rather than traditional culinary expertise or personal care. 
The business strategy adopted by another entrepreneur, Tapas, is similar to that of Keshab Babu and Gourmet Food. He was a young boy when he started helping his mother with her home delivery business, which she started after her husband lost his job. Tapas' father bought him a bicycle to carry food to clients in the neighbourhood. He grew up to study hotel and catering management and worked in hotels for a while. Having gained vital experience in the hospitality industry and accumulated some capital, he gave up his hotel job and set about developing and diversifying his mother's original home delivery business into an enterprise to cater for major events. He believes there is now more money to be made in catering than in many other fields. In his new venture, he has systematically moved away from low value daily family customers to cater to the entertainment industry and the private corporate sector. His work now enables him to move in the circles of high fashion, film, celebrity and corporate business, which he greatly enjoys. Public life, as opposed to the private domain of the home and family, is where he thrives, unlike women entrepreneurs. Tapas' role models are male catering and restaurant entrepreneurs who have assumed iconic, celebrity status in India, especially those who have promoted regional, 'ethnic' or fusion gourmet cuisine. High-end gourmet food is now extremely popular among upwardly mobile professionals with high purchasing power, in their quest for new lifestyle and elevated status (KPMG, 2016). This same spirit has animated the growing demand for marketproduced 'retro' Bengali cuisine and heritage dishes as value-added products. Bengali food used to have no standing in posh and plush dining experience zones. North Indian Mughlai food, Chinese, 'Continental' (western/European) or other types of international cuisine were favoured for feasts and public events. However, as Tapas points out, this has changed, not least because of the emergence of highly regarded, upmarket restaurants offering classic Bengali cuisine. This trend can be traced to the pioneering work of the legendary entrepreneur and restaurateur Anjan Chatterjee, who started the nation-wide chain 'Oh! Calcutta', with several branches now in Kolkata. Around the same time, several other such outlets emerged in Kolkata, such as the chain called 'Bhajohari Manna', and restaurants like 'Aheli' and '6 Ballygunj Place', all engaged in the public revival of Bengali food. With this accretion in the public cultural worth of Bengali food, Tapas notes that it no longer carries the connotation of domesticity, but is associated with high status and the public revival of cultural heritage. Here, Bengali food is aligned with the home and the market in a radically different way from that of home delivery food for domestic consumption. Women entrepreneurs see traditional cuisine in terms of their personal skill and expertise, and as an art handed down the generations through female lineage, to be used to enhance the home and the family. For the male vendors, however, neo-Bengali 'ethnic' food is not for consumption in the privacy of the home. Instead, it is a business innovation that celebrates a newly reinvigorated culinary genre by pandering to the upwardly mobile hosts' desire to show-off, in public, their putative sophistication and upper-class taste and sensibility. It is with a keen awareness of the marketability of this invented tradition that Tapas has devoted himself to transforming his erstwhile family home delivery business to large-scale, major-event catering with a commercial logic and a market-savvy approach. 
As evident from these cases, men, unlike women, enter home delivery with an assessment of the market and future outlook, rather than merely for sufficient earnings to support the family. Even when they undertake home delivery in support of female members of the family, they try to scale up and move away to the more large-scale processes of corporate and major event catering. Men's perceived and actual skills are that of managing and growing any business, not particular to cooking, or even food, which happens to be the chosen field due to its profitability and growth potentials. The key skills here are of branding, marketing and business management, not cooking or offering a caring service, as in the case of women. It is interesting to note that none of the women entrepreneurs classify the demand for their food in terms of market segments or genres such as ethnic, regional, international, fusion, etc. They refer instead, from a caring, need-based perspective, to demands from various groups of customers, such as the elderly, students, couples, housewives, families and so on.

\section{Conclusion}

The above analysis of women's home delivery businesses shows that at the heart of home delivery lies the effective deployment of what women proudly see as their traditional and inherited cooking proficiency, and their superior and inherent gendered skill to offer a personalized, bespoke, caring service, unlike commercial outfits, that are believed to lack comparable affective, even fictive kinship, relationships with their clientele. These, of course, reinforce prevalent female stereotypes and gendered divisions of labour. Further, this gendered orientation limits the possibility of expansion and diversification of business by women, as often highlighted in development interventions with a yardstick of entrepreneurial success from a dominant male-gendered perspective. However, contrary to these prevalent notions, these women do not perceive their concentration on cooking and caring as an impediment, as revealed by the gendered analysis of skills and enterprise in this paper. Indeed, they see their unique selling point to be the smallness of scale with which comes the intimacy of personal, caring relationships. They judiciously nurture this ethos and sustain their business on a limited scale, unlike men. Most importantly, this gendered understanding of skill is inextricably linked with their personal biography and individual life course as well as self-esteem and self-identity, which they value intrinsically and which they appear unwilling to compromise, even at the cost of constraining the potentials of their business to grow. Indeed, normatively, these women entrepreneurs appear to construe growth, at the cost of personalized caring, to be undesirable as well as inconsistent with their self-conception. Their use and nurture of skills are not only socially embedded or culturally rooted, but also subjectively understood and emotionally experienced. Family duties had prompted these entrepreneurs to use their cooking skills to embark on their enterprise, but they did not simply develop and rely on their skills as expert cooks, which would have been sufficient to conduct their business. Instead, they actively cast themselves as caring, nurturing persons, working honestly for the benefit of their clients, helping to consolidate homes and uphold familial relationships. There may be an element of marketing strategy in this approach, but much more importantly, this is a source of pride and 
satisfaction for them. It offers a powerful and appealing mode of self-making and self-realization to these women, transcending the everyday grind of back-breaking work for their business to support their families.

The skills deployed here are not learned through formal training in 'soft skills', as in corporate hospitality settings, but derived from an intuitive, common sense as well as a keen appreciation of human relationships and identity from life experience. In this context, women's subjective, affective skills are not seen by them merely as marketable assets. Affect and emotion are not straightforwardly commodified and pressed into action for business, as in the 'soft capitalism' of corporate enterprise (Hochschild, 1983; Illouz, 2008; Macdonald and Sirianni, 1996). Rather, from the perspective of these women, these skills are important to them as individuals, for they can develop a self-understanding as uniquely capable of care and nurture. This is what animates their powerful urge to develop and exercise these skills in particular ways, well beyond their efficacy in promoting business or earnings. This demonstrates that, both analytically and in policy terms, the perception of the possessor and user of skills is of utmost significance in understanding which skills might appeal to particular groups or individuals and how and why they might use and cultivate such skills, beyond the limited instrumental logic of income-generation and livelihood. These evidently non-utilitarian ideas about skill are, of course, compatible with the well-established conception of human development as an approach to advance human flourishing. To design effective and ethically desirable skill training programmes, it is critical, not just to take on board the needs of employers and the goals of economic growth and employment generation, but also to factor in the attitudes of workers or trainees and their subjective understanding of skills in a given context.

\section{Acknowledgement}

The research for this paper was conducted with the help of a grant from the John Fell Fund of University of Oxford.

\section{References}

Ahl, H. and Marlow, S. (2012) Exploring the dynamics of gender, feminism and entrepreneurship: Advancing debate to escape a dead end? Organization, 19(5), 543-562.

Bauman, Z. (1998). Work, consumerism and the new poor. Buckingham: Open University Press.

Bijapurkar, R. (2008). Winning in the Indian market: Understanding the transformation of consumer India. Singapore: John Wiley (Asia).

Billet, S. (2006). Relational interdependence between social and individual agency in work and working life. Mind, Culture and Activity, 13(1), 53-69. 
Bolton, S.C. (2004). Emotion work as skilled work. In C. Warhurst, E. Keep and I. Grugulis (Eds), The skills that matter (pp. 19-37). Basingstoke: Palgrave Macmillan.

Bruni, A., Gherardi, S. and Poggio, B. (2004). Doing gender, doing entrepreneurship: An ethnographic account of intertwined practices. Gender, Work and Organization, 11(4), 406-429.

Bruni, A., Gherardi, S. and Poggio, B. (2005). Gender and entrepreneurship: An ethnographic approach. London, New York: Routledge.

Butler, J. (1988). Performative Acts and Gender Constitution: An Essay in Phenomenology and Feminist Theory, Theatre Journal, 40(4), 519-531.

Butler, J. (1990). Gender trouble: Feminism and the subversion of identity. London, New York: Routledge.

Carswell, G. and De Neve, G. (2018). Towards a political economy of skill and garment work: The case of the Tiruppur industrial cluster in south India. In C. Hann and J. Parry (Eds), Industrial labor on the margins of capitalism: Precarity, Class and the Neoliberal Subject (pp. 309-335). New York, London: Berghahn Books.

Chatterjee, P. (1994). The nation and its fragments: Colonial and post-colonial histories. Delhi: Oxford University Press.

Donner, H. (2006). Committed mothers and well-adjusted children: Privatisation, early-years education and motherhood in Calcutta. Modern Asian Studies, 40(2), 371-95.

Donner, H. (2008). Domestic goddesses: Maternity, globalization and middle-class identity in contemporary India. Aldershot: Ashgate.

Donner, H. (2011). Gendered bodies, domestic work and perfect families: New regimes of gender and food in Bengali middle-class lifetsyles. In H. Donner (Ed.), Being middle-class in India: A way of life (pp. 47-72). London, New York: Routledge.

Ganguly-Scrase, R. (2003). Paradoxes of globalization, liberalization, and gender equality: The worldviews of the lower middle-class in West Bengal, India. Gender and Society, 17 (4), 544566.

Gaskell, J. (1987). Gender and Skill. In D.W. Livingstone (Ed), Critical pedagogy and cultural power (pp. 137-153). London: Palgrave. 
Gooptu, N. and Chakravarty, R. (2013). Reality TV in India and the making of an enterprising housewife. In N. Gooptu (Ed), Enterprise culture in neoliberal India: Studies in youth, class, work and media (pp. 140-155). London: Routledge.

Government of India. (n.d.). National Skill Development Mission: A framework for implementation, Ministry of Skill Development and Entrepreneurship, New Delhi. http://www.skilldevelopment.gov.in/assets/images/Mission\%20booklet.pdf (accessed 31 July 2018).

Heelas, P. (2002). Work ethics, soft capitalism and the 'turn to life'. In P. du Gay and M. Pryke (Eds), Cultural economy: Cultural analysis and commercial life (pp. 78-96). London, Thousand Oaks, New Delhi: Sage Publications.

Hochschild, A. (1983). The managed heart: Commercialization of human feeling. Berkeley, London: University of California Press.

Hochschild, A. (2012). The outsourced self: Intimate life in market times. New York: Metropolitan Books.

Illouz, E. (2008). Saving the modern soul: Therapy, emotions and the culture of self-help. Berkeley: University of California Press.

ILO. (2014). The gender divide in skills development: Progress, challenges and policy options for empowering women. Skills for Employment: Policy brief. Geneva: International Labour Office.

Janeja, M. (2010). Transactions in taste: The collaborative lives of everyday Bengali food. New Delhi: Routledge.

Joyce, P. (Ed.) (1987). The historical meanings of work. Cambridge: Cambridge University Press.

Kocka, J. (2010). Work in a modern society: The German historical experience in comparative perspective. New York, London: Berghahn Books.

KPMG (2016). India's food service industry: Growth recipe. https://assets.kpmg.com/content/dam/kpmg/in/pdf/2016/11/Indias-food-service.pdf (accessed 31 July 2018). 
Lloyd, C. and Payne, J. (2016) Skills in the Age of Over-Qualification: Comparing service sector work in Europe. Oxford: Oxford University Press.

Macdonald, C.L. and Sirianni, C. (1996). Working in the service society. Philadelphia: Temple University Press.

McGrath, S. (2012). Vocational education and training for development: A policy in need of a theory? International Journal of Educational Development, 32, 623-631.

Nandy, A. (2004). The changing popular culture of Indian food: Preliminary notes. South Asia Research, 24(1), 9-19.

Pal, C. (2016). Old is gold: How Kolkata's greying population is feeding a new kind of business. Scroll.in, 9 February. https://scroll.in/article/802543/old-is-gold-how-kolkatas-greyingpopulation-is-feeding-a-new-kind-of-business (accessed 31 July 2018).

Ray, R. and Qayum, S. (2009). Cultures of servitude: Modernity, domesticity, and class in India. Stanford: Stanford University Press.

Sarkar, T. (1981). Hindu wife and Hindu nation: Community, religion and cultural nationalism. London: Hurst.

Sen, S. (2015). Kolkata is ageing faster than other metros. Times of India (City: Kolkata), 27 October. https://timesofindia.indiatimes.com/city/kolkata/Kolkata-is-ageing-faster-than-othermetros/articleshow/49546289.cms (accessed 31 July 2018).

Srivastava, S. (2012). National identity, kitchens and bedrooms: Gated communities and new narratives of space in India. In M. Liechty, C. Freeman and R. Heiman (Eds), The global middleclasses: Theorizing through ethnography (pp. 57-84). Santa Fe: School of Advanced Research Press.

Thrift, N. (1997). The rise of soft capitalism. Cultural Values, 1(1), 29-57.

Urciuoli, B. (2008). Skills and selves in the new workplace. American Ethnologist, 35(2), 211228. 